\title{
Transdermal diclofenac patch $v s$ eutectic mixture of local anesthetics for venous cannulation pain
}

\author{
[Le diclofenac transdermique vs un mélange eutectique d'anesthésiques locaux \\ dans le traitement de la douleur associée au cathétérisme veineux]
}

Anil Agarwal MD, Sujeet Gautam MBBS, Devendra Gupta MD, Uttam Singh PhD

Purpose: To compare the efficacy and side effects of transdermal diclofenac patch with eutectic mixture of local anesthetic (EMLA) cream in attenuating venous cannulation pain.

Methods: Adult ASA I or II patients undergoing elective surgery were randomly divided into three groups of 150 each. Group I (Control) patients received a placebo patch; Group 2 (EMLA) patients received EMLA cream; Group 3 (Diclofenac) patients received a transdermal diclofenac patch. The patches were applied at the proposed venous cannulation site $60 \mathrm{~min}$ prior to cannulation and pain resulting from an I8G cannula was assessed on an ten-point visual analogue scale (VAS). The cannulation site was observed for blanching, erythema, induration and edema for up to $24 \mathrm{hr}$.

Results: The incidence of venous cannulation pain was $100 \%$ in the control group, as compared to $37 \%$ and $48 \%$ of patients who experienced pain in the EMLA $(P=0.00 \mathrm{I})$ and diclofenac $(P=0.00 \mathrm{I})$ groups, respectively. The severity of venous cannulation pain [median (VAS) with interquartile ranges] was also higher in the control group: 6 (3) as compared to VAS sores of $0(\mathrm{I})$ and $0(2)$ in the EMLA $(P=0.00 \mathrm{I})$ and diclofenac $(P=$ $0.00 \mathrm{I})$ groups. Blanching occurred with greater frequency in the EMLA group compared with the diclofenac $(P=0.001$ at six hours) and placebo groups ( $P=0.00 \mathrm{I}$ at six hours). Erythema, induration and edema were reduced in the diclofenac group compared with the EMLA ( $P=0.001$ for all comparisons) and placebo groups $(P=0.04$ for edema at six hours and $P=0.00$ I for other comparisons).

Conclusion: Transdermal diclofenac patch and EMLA are equally effective in reducing venous cannulation pain, but signs of erythema, induration and edema are less frequently observed with the transdermal diclofenac patch.
Objectif: Comparer l'efficacité et les effets secondaires du diclofenac transdermique au mélange eutectique d'anesthésiants locaux en crème $(E M L A \AA)$ pour atténuer les douleurs associées au cathétérisme veineux.

Méthode: Des patients adultes ASA I et II devant subir une chirurgie élective ont été randomisés en trois groupes de 150. Un timbre placebo a été donné au groupe I (témoin) ; le groupe 2 $(E M L A \circledast)$ a reçu la crème $E M L A \circledast$; le groupe 3 a reçu un timbre de diclofenac transdermique. Les timbres ont été appliqués au site prévu de canulation veineuse $60 \mathrm{~min}$ avant le cathétérisme, et la douleur provoquée par une canule de $18 \mathrm{G}$ a été évaluée sur une échelle visuelle analogue de onze points (EVA). L'apparition de blanchiment, d'érythème, d'induration ou d'œdème de la peau au site de canulation a été surveillée jusqu'à $24 \mathrm{~h}$.

Résultats: L'incidence de douleur associée à la canulation veineuse fut de $100 \%$ dans le groupe témoin, comparée à $37 \%$ et $48 \%$ dans les groupes EMLA ${ }^{\circledR}(P=0,00 I)$ et diclofenac $(P=$ $0,001)$ respectivement. La sévérité de la douleur associée à la canulation veineuse [(EVA) médian avec variations de quartile] fut également plus élevée dans le groupe témoin : 6 (3) sur l'échelle EVA comparé à $O(I)$ et $O(2)$ dans les groupes $E M L A \circledast(P=0,00 I)$ et diclofenac $(P=0,00 \mathrm{I})$. L'apparition de blanchiment cutané fut plus fréquente dans le groupe $E M L A \circledast$ comparé aux groupes diclofenac $(P=0,001$ à six heures) et placebo ( $P=0,001$ à six heures). Les érythèmes, indurations et oedèmes furent diminués dans le groupe diclofenac comparé aux groupes EMLA® $(P=0,001$ pour toutes les comparaisons) et placebo $(P=0,04$ pour l'œdème à six heures et $P=0,00$ I pour les autres comparaisons).

Conclusion : Le diclofenac transdermique et la crème EMLA® sont tous deux efficaces pour réduire la douleur associée à la ponction veineuse, mais les signes d'érythème, d'induration et d'œdème cutané sont moins fréquents avec le diclofenac transdermique.

CAN J ANESTH 2007 / 54: 3 / pp 196-200

From the Department of Anaesthesia and Biostatistics, Sanjay Gandhi Post Graduate Institute of Medical Sciences, Lucknow, India. Address correspondence to: Dr. Anil Agarwal, Type IV/48, SGPGIMS, Lucknow 226 014, India. Phone: +91 9451795500 ;

Fax: +91 522 2668017; E -mail: aagarwal@sgpgi.ac.in

Source of financial support: Nil.

Accepted for publication October 30, 2006.

Revision accepted December 4, 2006. 
$\mathrm{F}$ EAR of pain and anxiety associated with venous cannulation may contribute to overall stress experienced by patients in the perioperative setting. In addition, the reported incidence of iv device-related thrombophlebitis in a large series of over 10,000 surgical patients has been reported to be $10.3 \%$, with a lower incidence of bacteremia for peripheral, compared to central venous devices. ${ }^{1}$ Thrombophlebitis contributes to postoperative patient discomfort, and is clinically recognized by the presence of erythema, induration, and edema. ${ }^{2}$

A number of strategies to minimize the pain of venous cannulation for surgical patients are available, including local skin infiltration, topical application of eutectic mixture of local anesthetics (EMLA) or nonsteroidal anti-inflammatory drugs (NSAIDs), ethyl chloride spray, inhalation of nitrous oxide, ibuprofen and others. ${ }^{2-10}$ Each technique has advantages as well as limitations, but none has been shown to be effective in reducing both venous cannulation pain and peripheral venous thrombophlebitis (PVT). Interestingly, EMLA cream, one of the popular methods for decreasing venepuncture pain, is associated with skin blanching. ${ }^{11,12}$ Recently, a transdermal diclofenac patch (TDP) has been reported to be effective in attenuating venous cannulation pain. ${ }^{13}$ We therefore undertook a randomized controlled trial to compare TDP vs EMLA cream with respect to the incidence of venous cannulation pain, and PVT associated with peripheral venous cannulation.

\section{Methods}

The study protocol for this placebo-controlled, double-blind, randomized controlled trial was approved by the Research Ethics Board of the Sanjay Gandhi Post Graduate Institute of Medical Sciences. Written informed consent was obtained from each patient. We enrolled 450 adult patients (18-60 yr), of either sex and ASA physical status I or II, who were scheduled for elective endo-urological procedures, including ureteroscopy, direct visual internal urethrotomy and bladder cystoscopy. Patients were recruited over the period from January 2005 to June 2006. Excluded were patients with known sensitivity to local anesthetics, allergy to NSAIDs, and those with skin lesions at the site of application, skin infection, history of analgesic intake within the previous $24 \mathrm{hr}$, and inability to communicate.

Patients were randomly allocated according to a computer generated table of random numbers, into three groups of 150 each. Patients in Group 1 (Control) received a placebo patch, Group 2 patients (EMLA) received a thick layer of EMLA cream (Neon
Laboratories, Mumbai, India) $2 \mathrm{~g}$ per $10 \mathrm{~cm}^{2}$ and thereafter covered by placebo patch; whereas Group 3 (Diclofenac) patients received a DTP (NuPatch 100, Zydus Cadila, Ahemdabad, India) containing diclofenac diethylamine BP $100 \mathrm{mg}$, with an absorption area of $50 \mathrm{~cm}^{2}$. The placebo patches were similar to the diclofenac patches in appearance and were supplied by Zydus Cadila, Ahemdabad, India. All patches were applied at the proposed venous cannulation site on the dorsum of patient's non-dominant hand, one hour prior to venous cannulation. Patients were blinded to the type of patch received. Patches were applied and removed by a blinded preoperative staff nurse who was not otherwise involved in this study.

Intravenous cannulation was thereafter performed by an anesthesia consultant (D.G.) who was unaware of group allocation. Venous cannulation was performed using an 18G cannula (Angiocath SP TM Becton Dickinson India Ltd). An anesthesia registrar (S.G.) who was also blinded to group allocation, recorded the pain scores as rated by patients on a visual analogue scale (VAS) $0-10 \mathrm{~cm} \mathrm{(0=} \mathrm{no} \mathrm{pain,} 10=$ worst possible pain). The site of venous cannulation was observed for the presence of blanching, erythema, induration and edema at the time of cannulation and thereafter, up to a period of $24 \mathrm{hr}$ postoperatively. Patients whose veins could not be cannulated successfully on the first attempt were considered as initial cannulation failures and were not queried regarding the occurrence of pain and VAS scores; these patients were also not observed for the occurrence of blanching, erythema, induration and edema in the postoperative period.

Assuming that there would be a $30 \%$ reduction in the incidence of venous cannulation pain following therapy, 29 patients per group would be required for a significance level $\alpha=0.05$, and $\beta=0.95$. However, 133 patients per group were required to demonstrate a reduction in the incidence of PVT from $57 \%$ to $40 \%$, with $\alpha=0.05$ and $\beta=0.80$. We therefore enrolled 150 patients per group to account for potential drop-outs or protocol violations. The Chi-square statistic was used to compare pain data, number of initial cannulation failures in the three groups, and for comparison

TABLE I Patient demographics

\begin{tabular}{llll}
\hline Groups & Control & EMLA & Diclofenac \\
\hline$n$ & 150 & 150 & 150 \\
Age (yr) & $42.9 \pm 10.7$ & $42.7 \pm 14.3$ & $42.9 \pm 10.2$ \\
Weight $(\mathrm{kg})$ & $55.8 \pm 9.3$ & $56.6 \pm 10.2$ & $54.9 \pm 10.1$ \\
Sex $(\mathrm{M} / \mathrm{F})$ & $109 / 41$ & $120 / 30$ & $115 / 35$ \\
\hline
\end{tabular}

Data are presented as either mean values \pm SD or by absolute numbers. EMLA = eutectic mixture of local anesthetics. 


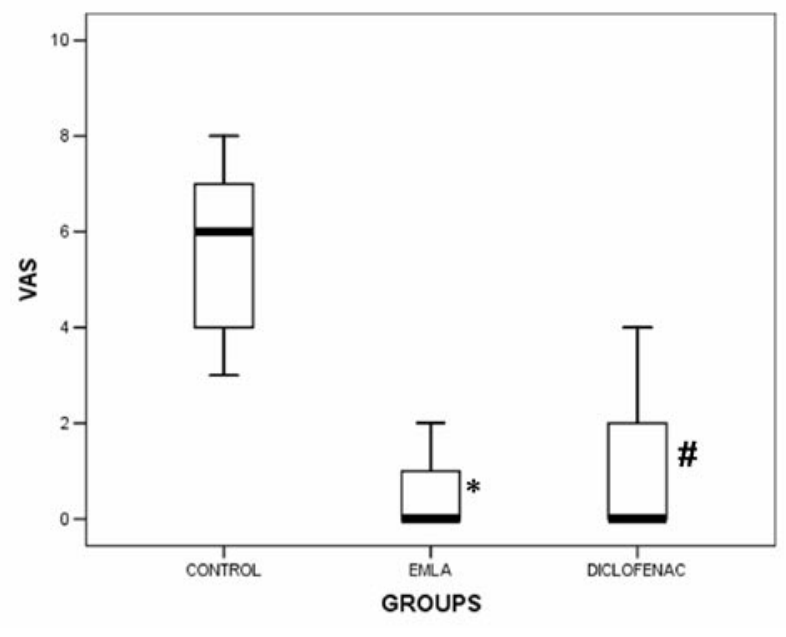

FIGURE Venous cannulation pain as assessed by a visual analogue scale (VAS). Data are presented as medians with interquartile ranges. ${ }^{*} P<0.05$, inter-group comparison of control vs EMLA groups. \# $P<0.05$, inter-group comparison of control $v s$ the diclofenac group. EMLA = eutectic mixture of local anesthetics.

of the frequency of skin reactions between the three groups. The VAS pain scores were compared using the Mann Whitney U test. The package SPSS 9.0 (SPSS Inc, Chicago, IL, USA) was used for statistical analysis. $P<0.05$ was considered significant.

\section{Results}

Of 585 patients who were screened, 450 consented and were recruited for the study, and subsequently randomized. Thirty-five patients (ten, 16 and nine in the control, EMLA and diclofenac groups respectively) could not be cannulated in the first attempt, and were not considered for statistical analysis with respect to occurrence of pain and assessment of severity of pain, blanching and signs of PVT. These patients were, however, included in the demographic analysis.
No significant differences were observed amongst the patients who were initial cannulation failures. Groups were similar with respect to demographic characteristics (Table I).

All patients in the control group experienced pain in response to venous cannulation $(140 / 140)$ compared to $37 \%(49 / 134)$ and $48 \%(67 / 141)$ of patients in the EMLA $(P=0.001$ vs placebo $)$ and TDP $(P$ $=0.001 \mathrm{vs}$ placebo) groups. The severity of venous cannulation pain as assessed by median VAS scores (interquartile range) in the control group was $6(3)$ as compared to $0(1)$ and $0(2)$ in the EMLA $(P=0.001)$ and diclofenac $(P=0.001)$ groups. The incidence and severity of venous cannulation pain was similar in the EMLA and diclofenac groups $(P=0.053$, Figure $)$.

Skin blanching was observed in $73 \%$ of patients in the EMLA group at the time of venous cannulation (0 hr), which resolved over $24 \mathrm{hr}$, as compared to no patients with blanching in either the diclofenac or placebo groups (Table II). Erythema and edema at the venous cannulation site was more frequent in the EMLA group at six hours when compared with the control group (Table II; $P=0.001$ and 0.01 for erythema and edema respectively). In the diclofenac group, the incidence of induration and edema at the cannulation site was reduced at six, 12 and $24 \mathrm{hr}$ following venous cannulation when compared with EMLA $(P=0.001$ for all comparisons $)$ and placebo groups $(P=0.04$ for edema at six hours and $P=0.001$ for other comparisons) (Table II); the incidence of erythema was reduced in the diclofenac group at 12 and $24 \mathrm{hr}$ following venous cannulation compared with other two groups (Table II; $P=0.001$ for all comparisons).

The numbers needed-to-treat (NNT) for a reduction of pain in the EMLA and diclofenac groups were 2 ; whereas, for thrombophlebitis the NNT were 13 and 3 in the EMLA and diclofenac groups, respectively.

TABLE II Skin reactions at the site of venous cannulation

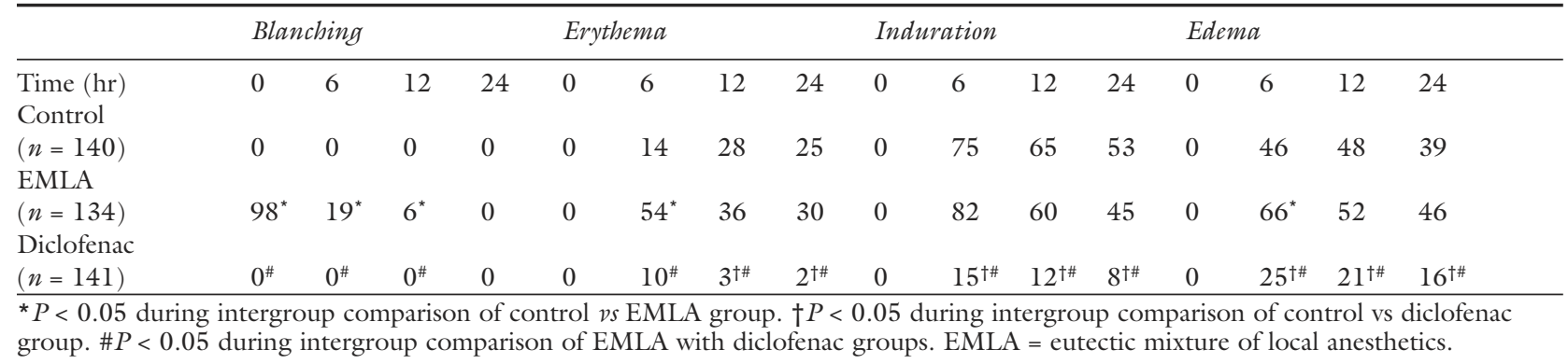




\section{Discussion}

We observed that TDP and topical application of EMLA cream are equally effective in reducing both the incidence and severity of venous cannulation pain. However, a higher incidence of skin blanching associated with EMLA cream and a reduced incidence of PVT with the TDP patch suggest advantages with the TDP.

Application of EMLA cream (eutectic mixture of $2.5 \%$ lidocaine with $2.5 \%$ prilocaine) is an effective method for prevention of venous cannulation pain, but is associated with skin blanching at the site of application as a result of localized vasoconstriction. ${ }^{11,12}$ In the present study we observed that more patients (16/150) could not be cannulated on the first attempt in the EMLA group, as compared to $10 / 150$ and $9 / 150$ patients in the control and diclofenac groups respectively. While vasoconstriction caused by EMLA cream could have been a contributing factor, the numerical differences in failure rates did not achieve statistical significance.

Other side effects associated with EMLA cream include methemoglobinemia, erythema, urticaria, allergic contact dermatitis, irritant contact dermatitis, hyper-pigmentation and purpura. ${ }^{11,12}$ The cutaneous manifestations observed in the EMLA group in the current study had resolved within six hours of application. The initial higher incidence of erythema and induration with EMLA cream may possibly be due to the fact that EMLA is known to cause an initial localized vasoconstriction leading to blanching followed by vasodilatation, resulting in erythema and induration. ${ }^{11,12}$ This erythema and induration subside as the vasodilatation resolves.

Non-steroidal anti-inflammatory drugs are known to be effective analgesics. Topically-applied NSAIDs are effective in decreasing both acute and chronic pain; ${ }^{14}$ they inhibit prostaglandin synthesis at the site of application, and decrease the inflammatory response to cannulation. ${ }^{12}$ Topical NSAIDs offer the advantage of enhanced local drug delivery to the affected tissues with a lower incidence of adverse systemic effects as a result of decreased plasma concentrations. ${ }^{15}$ In addition, topical NSAIDs have been associated with a lower incidence of gastrointestinal adverse effects compared with oral administration of these medications. ${ }^{16}$ Topical application of NSAID gel at the cannulation site reduces the incidence of PVT following iv cannulation; this reduction in thrombophlebitis has been attributed to the anti-inflammatory nature of the NSAID gel. ${ }^{2}$ Dutta et al. reported that topical application of piroxicam gel before iv cannulation reduces inflammatory changes at the cannulation site, although it is ineffective in reducing venepuncture pain. ${ }^{12}$ The TDP has been shown to be effective in attenuating venous cannulation pain, ${ }^{13}$ with the most frequently observed adverse effects being pruritus and a mild rash, occurring with similar frequency to placebo group. ${ }^{15}$ In the present study, no episodes of pruritus, rash or asthma were observed.

The frequencies of erythema, induration and edema in the diclofenac group were lower compared to the other two groups. The TDP also reduced the incidence and severity of venous cannulation pain, which was comparable to EMLA. Agarwal et al. reported a median VAS score of $3(2.0-4.0)$ in response to a TDP, as compared to $0(2)$ in the present study. ${ }^{13}$ The observed discrepancy could reflect, in part, a six-fold variance in the sample size of the two studies. However, the differences in VAS scores of the two studies is of modest clinical importance, as VAS scores in both groups fell within the mild pain category (scores of $0-3$ ).

This study has several limitations, including the fact that fluid composition and volumes of infusion through the iv line were not standardized. Further, the duration of cannulation and a specific anesthetic protocol were not established. However, the overall influence of these variables on the primary and secondary outcomes of interest were likely to have been very modest.

In conclusion, the TDP patch and EMLA cream are equally effective in reducing the incidence and severity of venous cannulation pain. However, a higher incidence of skin blanching associated with EMLA cream and a lower incidence of signs of PVT following the TDP favour consideration of the TDP. We suggest that a TDP applied at the proposed cannulation site one hour prior to venous cannulation is an effective and safe method for attenuating venous cannulation pain with minimal local skin reaction.

\section{References}

1 Nystrom B, Larsen SO, Dankert J, et al. Bacteraemia in surgical patients with intravenous devices: a European multicentre incidence study. The European Working Party on Control of Hospital Infections. J Hosp Infect 1983; 4: 338-49.

2 Payne-James JJ, Bray MJ, Kapadia S, Rana SK, McSwiggan D, Silk DB. Topical nonsteroidal antiinflammatory gel for the prevention of peripheral vein thrombophlebitis. A double-blind, randomised, placebo-controlled trial in normal subjects. Anaesthesia 1992; 47: 324-6.

3 Lal MK, McClelland J, Phillips J, Taub NA, Beattie $R M$. Comparison of EMLA cream versus placebo in children receiving distraction therapy for venepuncture. 
Acta Paediatr 2001; 90: 154-9.

4 Armstrong P, Young C, McKeown D. Ethyl chloride and venepuncture pain: a comparison with intradermal lidocaine. Can J Anaesth 1990; 37: 656-8.

5 Henderson JM, Spence DG, Komocar LM, Bonn GE, Stenstrom RJ. Administration of nitrous oxide to pediatric patients provides analgesia for venous cannulation. Anesthesiology 1990; 72: 269-71.

6 Carlson KL, Broome M, Vessey JA. Using distraction to reduce reported pain, fear, and behavioral distress in children and adolescents: a multisite study. J Soc Pediatr Nurs 2000; 5: 75-85.

7 Usichenko TI, Pavlovic D, Foellner S, Wendt M. Reducing venipuncture pain by a cough trick: a randomized crossover volunteer study. Anesth Analg 2004; 98: 343-5.

8 Agarwal A, Sinha PK, Tandon M, Dhiraaj S, Singh $U$. Evaluating the efficacy of the valsalva maneuver on venous cannulation pain: a prospective, randomized study. Anesth Analg 2005; 101: 1230-2.

9 Gupta D, Agarwal A, Dhiraaj S, et al. An evaluation of efficacy of balloon inflation on venous cannulation pain in children: a prospective, randomized, controlled study. Anesth Analg 2006; 102: 1372-5.

10 Smith AJ, Eggers KA, Stacey MR. Topical ibuprofen for skin analgesia prior to venepuncture. Anaesthesia 1996; 51: 495-7.

11 Buckley MM, Benfield P. Eutectic lidocaine/prilocaine cream. A review of the topical anaesthetic/analgesic efficacy of a eutectic mixture of local anaesthetics (EMLA). Drugs 1993; 46: 126-51.

12 Dutta A, Puri GD, Wig J. Piroxicam gel, compared to EMLA cream is associated with less pain after venous cannulation in volunteers. Can J Anesth 2003; 50: 775-8.

13 Agarwal A, Dhiraaj S, Kumar A, Singhal V, Singh U. Evaluation of a diclofenac transdermal patch for the attenuation of venous cannulation pain: a prospective, randomised, double-blind, placebo-controlled study. Anaesthesia 2006; 61: 360-2.

14 Moore RA, Tramer MR, Carroll D, Wiffen PJ, McQuay $H J$. Quantitive systematic review of topically applied non-steroidal anti-inflammatory drugs. BMJ 1998; 316: 333-8.

15 Predel HG, Koll R, Pabst $H$, et al. Diclofenac patch for topical treatment of acute impact injuries: a randomised, double blind, placebo controlled, multicentre study. Br J Sports Med 2004; 38: 318-23.

16 Evans JM, McMahon AD, McGilchrist MM, et al. Topical non-steroidal anti-inflammatory drugs and admission to hospital for upper gastrointestinal bleeding and perforation: a record linkage case-control study. BMJ 1995; 311: 22-6. 